\title{
Estudio comparativo de técnicas de preparación de muestras para microscopía electrónica de transmisión de recubrimientos cerámicos proyectados por plasma
}

\author{
A. RAMÍREZ DE ARELLANO LÓPEZ ${ }^{1}$, W-A. CHIOU ${ }^{2}$, Y K.T. FABER ${ }^{2}$ \\ ${ }^{1}$ Dept. de Física de la Materia Condensada, Universidad de Sevilla \\ ${ }^{2}$ Dept. of Materials Science and Engineering, Northwestern University, Evanston, Illinois, EE.UU.
}

\begin{abstract}
El desarrollo de materiales avanzados, con microestructuras cada vez más complejas, supone un reto constante de desarrollo y aplicación de técnicas que permitan el análisis de la microestructura de forma eficiente. En el caso de los recubrimientos cerámicos sobre substrato metálico, la diferente velocidad de adelgazamiento iónico que suelen mostrar ambos sistemas supone, en principio, una limitación sustancial. En este trabajo, presentamos un estudio comparativo de la fabricación de láminas delgadas para microscopía electrónica de transmisión, empleando en primer lugar una técnica derivada de la convencional (desbaste, pulido y adelgazamiento iónico), y alternativamente una novedosa técnica de ataque selectivo mediante un haz iónico. El material elegido para realizar este estudio ha sido un recubrimiento de óxido de aluminio de grano fino proyectado por el método de plasma sobre acero. Se discute la eficiencia de cada una de las técnicas, así como las carácteristicas microstructurales más destacadas en el material objeto de estudio.
\end{abstract}

Palabras clave: recubrimientos, óxido de aluminio, acero, microestructura, microscopía electrónica de transmisión.

\section{Comparative study of TEM sample preparation techniques for plasma-sprayed ceramic coatings}

The development of advanced materials, with complex microstructures, is a permanent challenge to the development and application of new efficient techniques for microstructural characterization. In ceramic coatings on metals, there exist a differential ion-milling ratio between both components, limiting in principle the use of conventional techniques. In this work, we report on a comparative study of TEM sample preparation techniques for plasma-sprayed ceramic coatings. Firstly, we have used a procedure derived from the conventional one (polishing, dimpling, ion milling), and alternatively a new technique using focused ion-beam milling. The material selected for this study is fine-grained alumina that was plasmasprayed on a steel substrate. The efficiency of both techniques is discussed along with the most significant microstructural features of the material subject of study.

Key words: coatings, alumina, steel, microstructure, transmission electron microscopy.

\section{1.- INTRODUCCIÓN}

Los resultados de los estudios que emplean la técnica de microscopía electrónica de transmisión (TEM, siglas en inglés) para el análisis de materiales, dependen críticamente de la calidad de las láminas $(1,2)$. En el caso de muestras que contienen intercaras metal/cerámica, es bien sabido que el principal reto de la preparación de láminas para TEM, es el diferente ritmo de adelgazamiento que presentan ambos tipos de sólidos ante el ataque iónico convencional.

En fechas relativamente recientes, se ha desarrollado un sistema de adelgazamiento que permite el uso de un haz iónico focalizado (FIB, siglas en inglés), cuya intensidad y área de trabajo puede ser manipulada de forma precisa. Se espera que ello permita adecuar el trabajo de adelgazamiento a las características composicionales y morfológicas del material (3).

De forma resumida, el sistema funciona mediante la aceleración de iones térmicos extraídos de un filamento de Ga. Los iones impactan en un área seleccionada, con una energía y velocidad de barrido determinada. Tras un número de pasadas preestablecido, se puede proceder a la inspección del tra- bajo realizado mediante imágenes generadas por electrones secundarios que son extraídos de la muestra por la incidencia de los iones acelerados. Estas imágenes son análogas a las obtenidas mediante microscopía electrónica de barrido (SEM, siglas en inglés) convencional. Denominaremos el dispositivo por sus iniciales inglesas, FIB-SEM.

Este trabajo presenta un estudio comparativo de la eficiencia de las técnicas de adelgazamiento de tipo convencional y FIB, para la elaboración de láminas TEM de intercaras metal/ cerámico. La estrategia y resultados del proyecto se han seguido mediante microscopía óptica y electrónica, en los términos que se presentarán posteriormente.

Las interfases objeto de estudio se han producido mediante la proyección por plasma de óxido de aluminio de grano pequeño, sobre un substrato de acero desbastado. El proceso, desarrollado por Bernecki y Marron y cuyos detalles están protegidos por patente (4), está registrado con las siglas SPPS (Small Particle Plasma Spray), y permite proyectar granos de diámetro inferior a $40 \mathrm{~nm}$, mejorando las técnicas de proyección por plasma con- 
vencionales. La principal aplicación de estos recubrimientos se estima en la mejora de resistencia a la fricción, o alternativamente como intercapa de protección térmica $(5,6)$.

En el caso de los materiales utilizados en este trabajo, se proyectaron polvos de $\alpha-\mathrm{Al}_{2} \mathrm{O}_{3^{\prime}}$ de morfología regular y tamaño de grano promedio de $9 \mu \mathrm{m}$. Los granos funden en el plasma caliente, y solidifican rápidamente al impactar contra el substrato, adoptando una forma discoidal, que se denomina "splats" (7). Se pueden encontrar detalles adicionales sobre este proceso y sobre la evolución microestructural del recubrimiento en la literatura (8).

\section{2.- TÉCNICAS EXPERIMENTALES}

La figura 1 presenta un diagrama de flujo con el esquema de la estrategia que hemos seguido para este estudio. En primer lugar, mediante una sierra adiamantada de baja velocidad, y cortando perpendicularmente a la interfase, se prepararon pequeños paralelepípedos de dimensiones $2 \times 1 \times 1 \mathrm{~mm}$ y $15 \times 1 \times 1 \mathrm{~mm}$. El primer tipo se empleó para la producción de láminas individuales, mientras que el segundo se usó en las láminas que hemos denominado "duplex". Para la producción de éstas últimas, las barras 15x1x1mm se pegan con los recubrimientos enfrentados y se introducen en un tubo de vidrio de $2.5 \mathrm{~mm}$ de diámetro interior y $3.0 \mathrm{~mm}$ de diámetro exterior. Tras el endurecimiento de la resina epoxy, se procede a cortar una serie de "lonchas" de $0.5 \mathrm{~mm}$ de grosor a lo largo del tubo. A continuación, tanto las muestras individuales como las duplex se adelgazaron por pulido mecánico con papel de $\mathrm{SiC}$ hasta un grosor de unas $50 \mu \mathrm{m}$, con lo quedan listas para los pasos finales de preparación, que hemos realizado tanto por procedimientos convencionales como mediante FIB.

\section{1.- Técnicas de Preparación Convencionales}

Como se comprueba en la Figura 1a, el área objetivo final era distinta para las láminas individuales y las duplex. En las primeras, el pulido mecánico cóncavo y el ataque iónico tiene lugar fundamentalmente en el acero, mientras que en las muestras duplex éstos se producen en el recubrimiento de óxido de aluminio. En el primer caso se pretende acceder a la interfase desde el metal, y en el segundo desde el cerámico. Las láminas se montaron en una rejilla de cobre de $3 \mathrm{~mm}$ con un solo agujero. Para el adelgazamiento mecánico se utilizó un Dimpler VCR y para el adelgazamiento iónico un aparato Gatan Dual Ion-Milling.

Todo el proceso de adelgazamiento se siguió de forma periódica mediante microscopía óptica, lo que permitió obtener interesantes detalles microestructurales, como el que se presenta en la micrografía de la figura 2, en este caso de una lámina duplex, empleando luz transmitida. El grosor de esta zona es unos $5 \mu \mathrm{m}$, y la banda en el centro de la fotografía es el pegamento empleado para unir las muestras duplex. Se constata que el recubrimiento cerámico posee una estructura laminar, que se debe al barrido de la pistola de proyección del plasma. El mismo tipo de estructura laminar se observó en las muestras individuales (figura 3). Los detalles de la evolución de esta estructura laminar han sido objeto de otra publicación (9).

El tiempo típico de preparación ha sido del orden de un día/muestra para las láminas individuales y en torno a dos días/muestra para las láminas duplex. Tal como se preveía, en este proceso de preparación el acero se adelgaza más rápidamente que el óxido de aluminio, pero algunas zonas, tanto

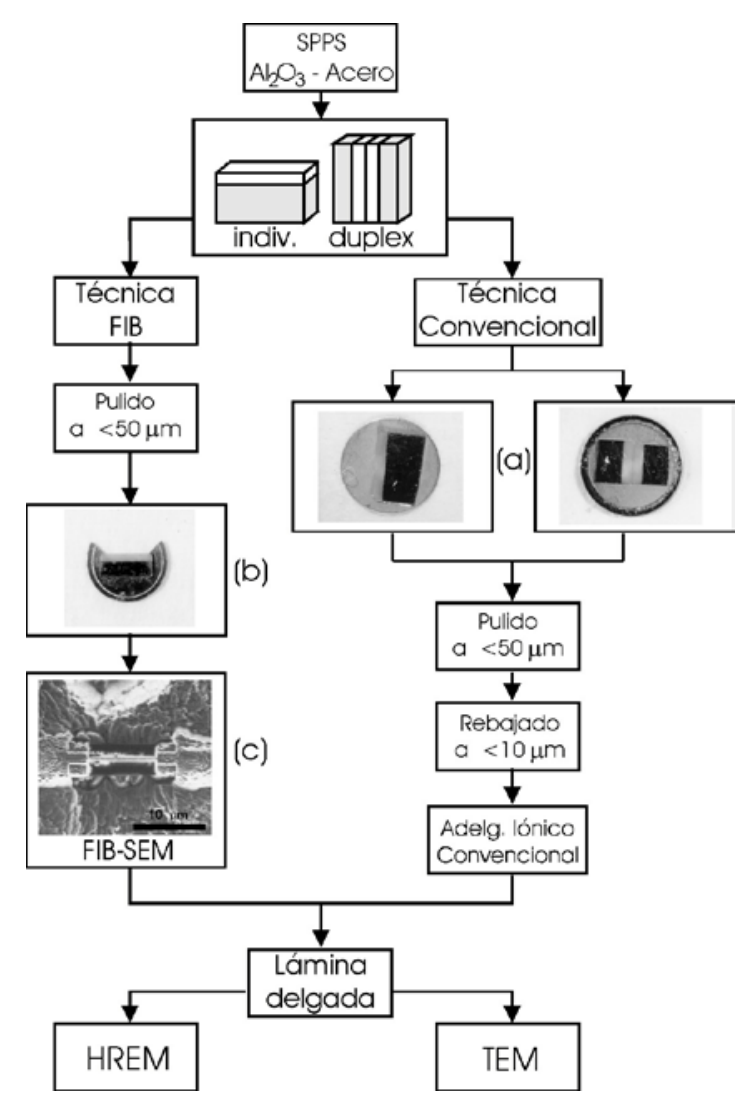

Figura 1. Diagrama de flujo del proceso de preparación de muestras. Las micrografías ópticas (a) y (b) presentan la disposición de las muestras en las rejillas para TEM (diámetro $\sim 3 \mathrm{~mm}$ ). La micrografía (c) es una imagen FIB-SEM del área de trabajo durante el desbaste empleando la técnica de haz focalizado. El marcador corresponde a $10 \mu \mathrm{m}$.

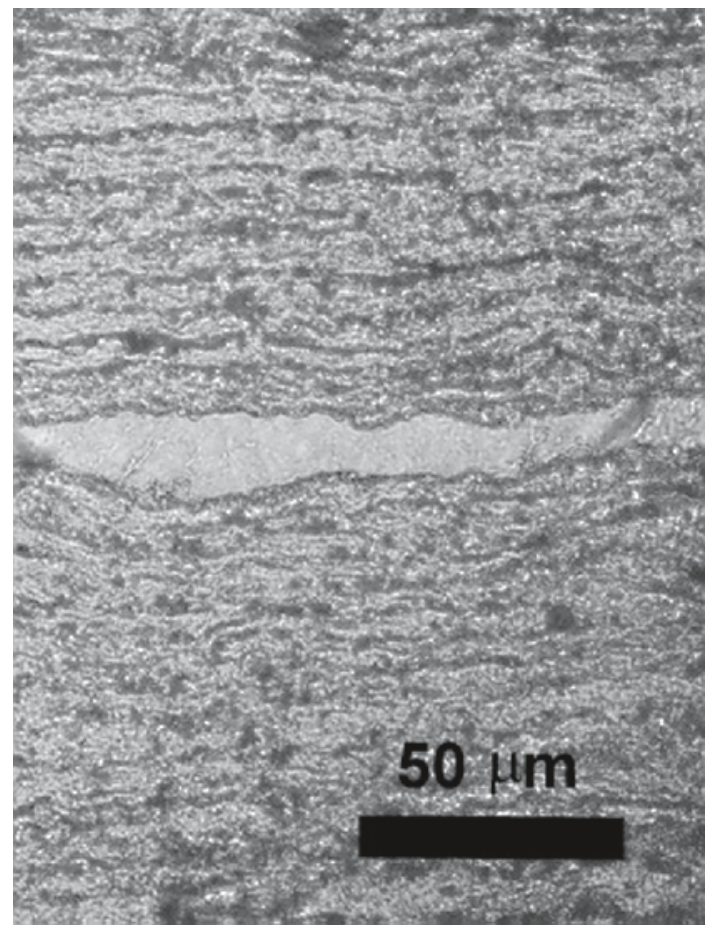

Figura 2. Micrografía óptica con luz transmitida de una zona adelgazada de una muestra duplex. Se comprueba la naturaleza laminar del recubrimiento. 


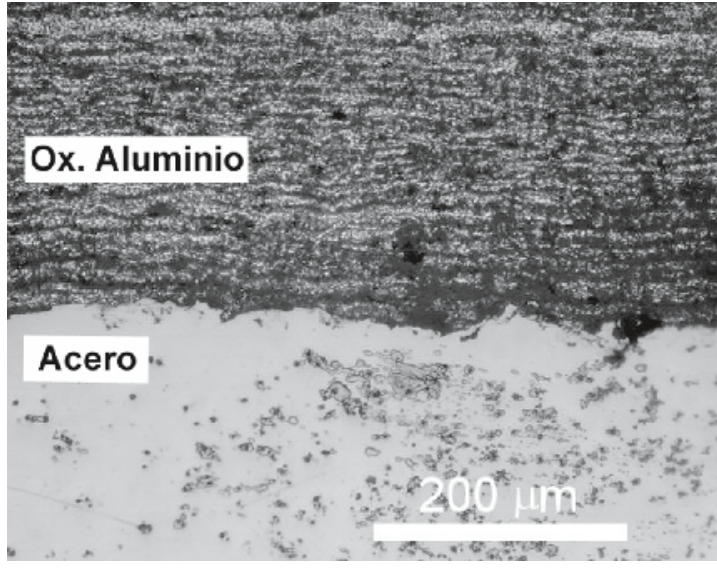

Figura 3.- Micrografía óptica con luz transmitida+reflejada de una zona adelgazada de una muestra individual.
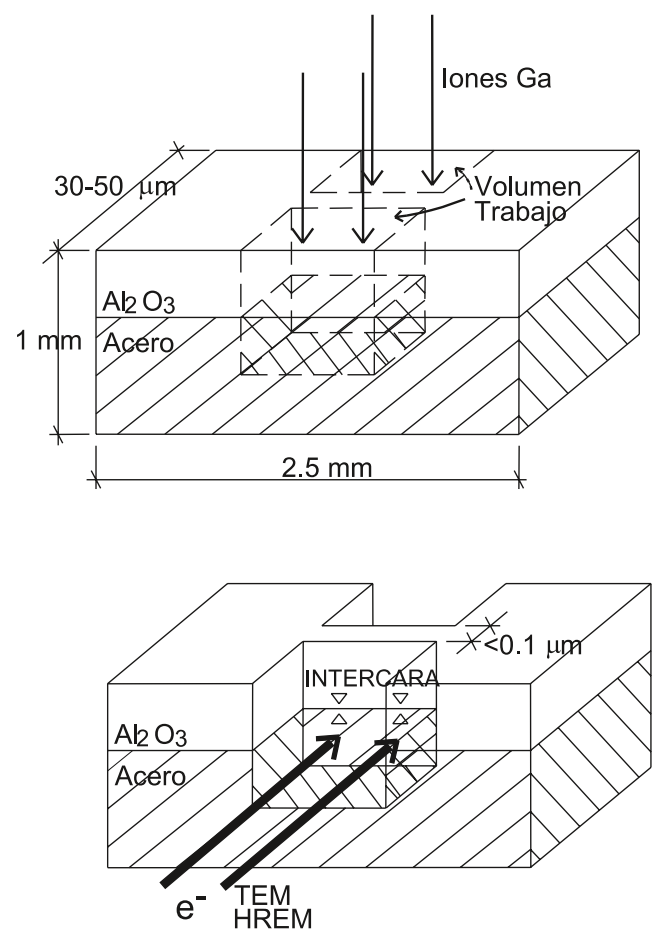

Figura 4.- Esquema de la estrategia de trabajo FIB.

de la interfase como del propio material cerámico, han resultado de excelente calidad para su observación por medio de TEM. Las muestras duplex han sido particularmente interesantes, pues presentan una extensa área de observación (de más de $80 \mu \mathrm{m}$ de diámetro) en el material cerámico. Por su parte, las muestras individuales han sido más adecuadas para el estudio de la interfase metal/cerámica, e incluso ha sido posible su observación mediante microscopía electrónica de alta resolución (HREM, en siglas en inglés)

\section{2.- Técnica de Preparación FIB}

Mediante la combinación de cortes y pulido, se ha preparado piezas de $2.5 \mathrm{~mm} \times 1 \mathrm{~mm} \times 30-40 \mu \mathrm{m}$, que luego se han montado sobre rejillas de molibdeno de $3 \mathrm{~mm}$ (figura $1 \mathrm{~b}$ ). Dado que nuestro objetivo principal es la intercara entre las fases, se rebajó el espesor del recubrimiento hasta unas 30/40 $\mu \mathrm{m}$ mediante pulido mecánico.
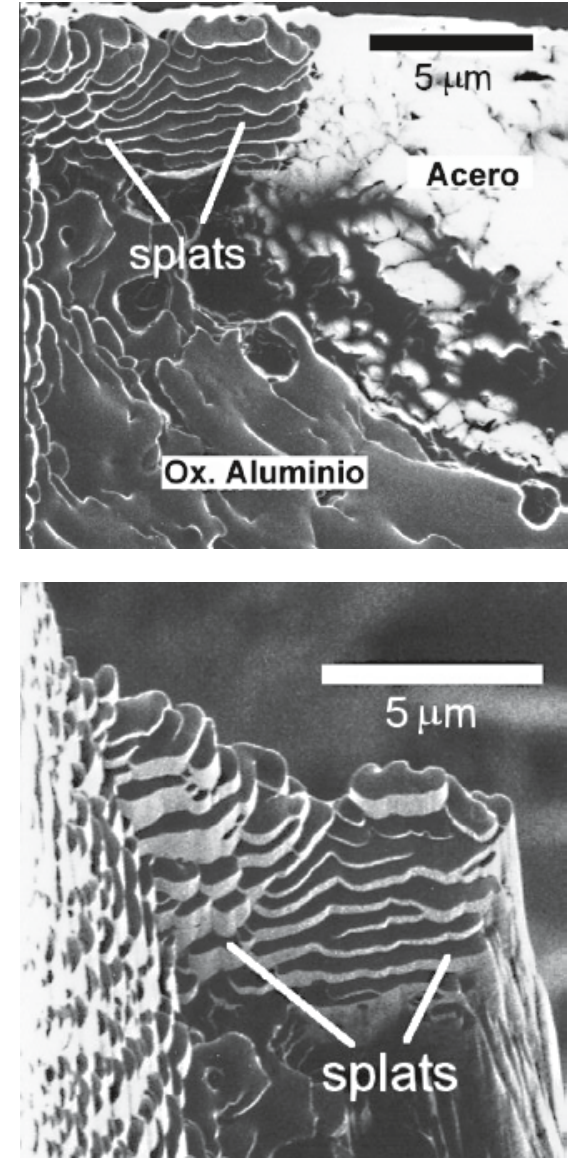

Figura 5.- Micrografías SEM mostrando la microestructura de la muestra, revelada durante el ataque FIB por la acción preferencial de los iones sobre las interfases entre splats.

Se ha empleado un FIB Hitachi 2000A (10), siguiendo el procedimiento de preparación que se esquematiza en la figura 4. Los iones de galio atacan inicialmente las muestras por el lado del material cerámico, despejando el camino hacia el acero. Manipulando el tamaño del área seleccionada, el tamaño de spot, y la energía se procede a un adelgazamiento gradual. El soporte de muestras del FIB Hitachi, está especialmente diseñado de forma que puede usarse directamente en el microscopio de transmisión, de forma que no hay que manipular adicionalmente la muestra adelgazada. Esto permite ir comprobando el grado de adelgazamiento y el momento en el que el área de trabajo es suficientemente transparente a los electrones, con el grosor adecuado.

Una interesante prestación del FIB es que la incidencia de los iones focalizados extrae electrones secundarios de las muestras, que son utilizables para generar imágenes SEM. Ello permite seguir in-situ el proceso de adelgazamiento, como se ve por ejemplo en la figura 1c. Usando FIB-SEM es posible revelar la estructura de granos-splat (figuras $5 a$ y $5 b$ ), debido a la acción preferente de los iones en las fronteras entre los granos.

El tiempo de preparación se reduce para las muestras FIB a sólo unas pocas horas, obteniéndose un área de observación de la misma calidad que la de las láminas convencionales. Como aspecto negativo, la superficie de observación es sólo de 5-10 $\mu \mathrm{m}$ de diámetro, aunque con la contraprestación de permitir acceder a zonas elegidas con un alto grado de precisión. 3.- RESULTADOS (MICROSCOPÍA ELECTRÓNICA DE 


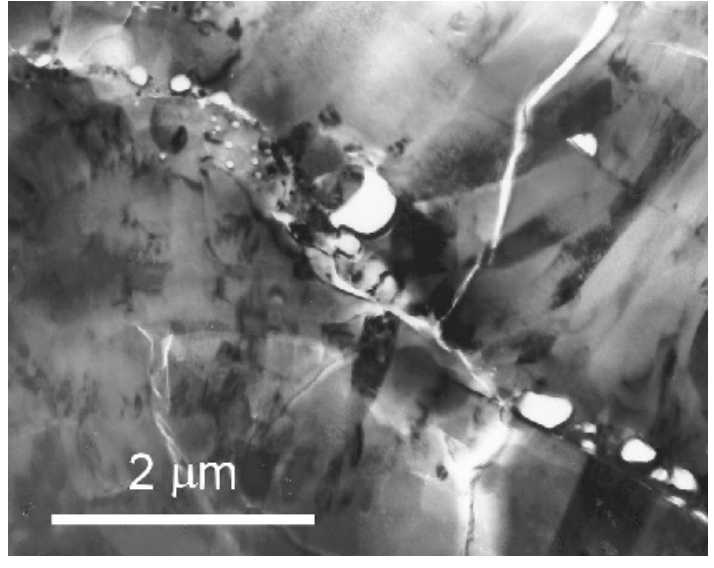

Figura 6.- Micrografía TEM de una muestra preparada por procedimientos convencionales. Se muestran las burbujas de gases atrapados en las fronteras entre splats.

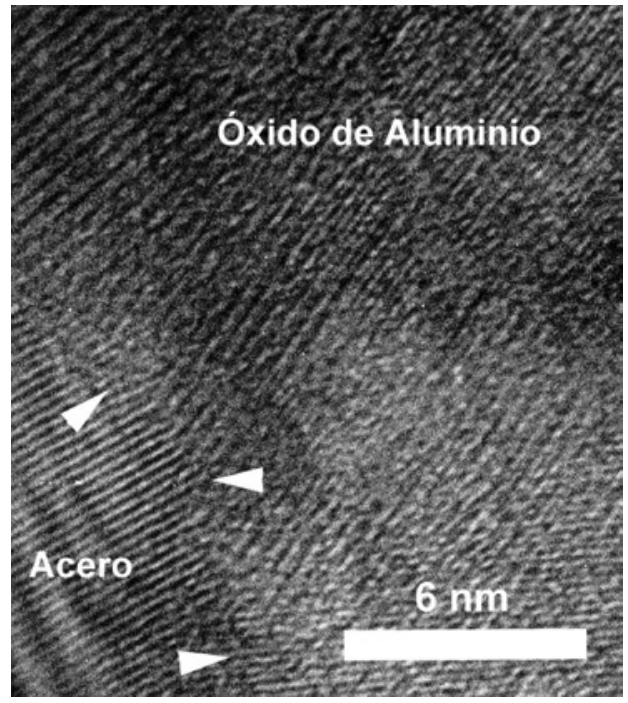

Figura 8.- Micrografía HREM de una muestra preparada por procedimientos convencionales, en la interfase metal/cerámica. Las flechas blancas marcan la interfase.

\section{TRANSMISIÓN)}

La micrografía de la figura 6 muestra el aspecto general del recubrimiento en una muestra duplex, preparada mediante técnica convencional. La estructura laminar, que se había puesto de manifiesto mediante microscopía óptica, es el resultado de conjuntos de cavidades que se agrupan en las fronteras entre los splats, paralelamente a la interfase metal/cerámica. Estas cavidades se originan por los gases atrapados por el rápido enfriamiento de los granos fundidos de óxido de aluminio. Se observan con claridad las secciones individuales de los splats, formando una estructura similar a una pared o muro de ladrillos.

La estructura cristalina de estos granos se puede identificar mediante difracción de electrones, aunque su tratamiento en detalle ha sido objeto de una publicación específica (9). Decir aquí únicamente que se ha detectado la presencia de $\gamma-\mathrm{Al}_{2} \mathrm{O}_{3}$, que es una forma con simetría cúbica y estructura tipo espinela, metaestable a temperatura ambiente, que sin duda será un factor de limitación en el ciclo térmico de los recubrimientos.

Por su parte, la interfase tiene áreas de contacto muy

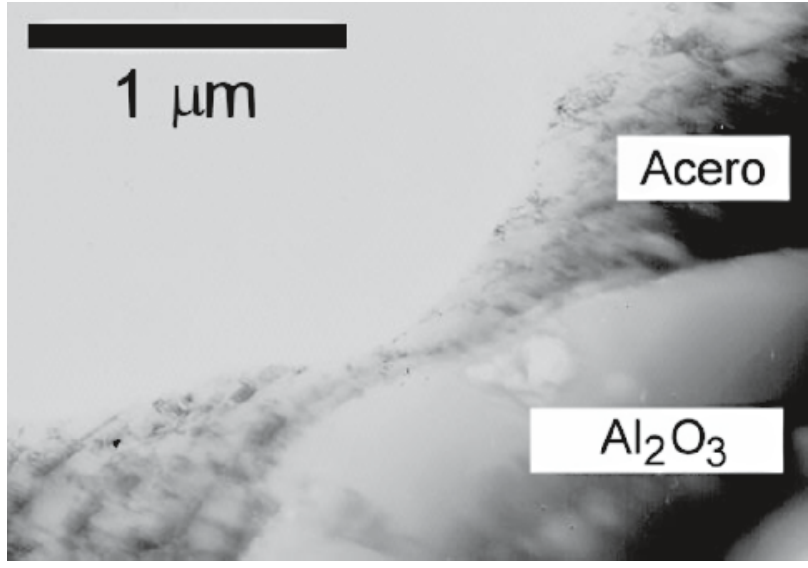

Figura 7.- Micrografía TEM de una muestra preparada por procedimientos convencionales, mostrando la unión metal/ cerámica.

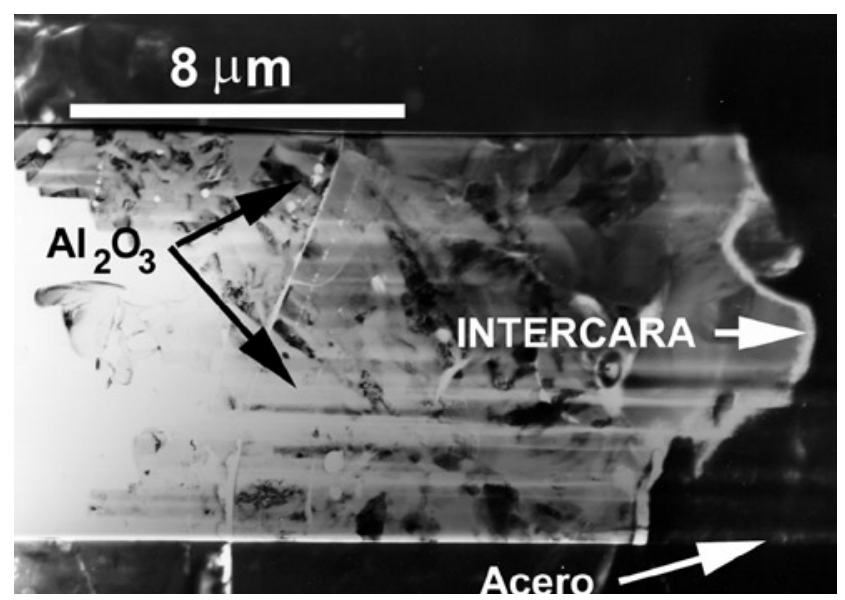

Figura 9.- Micrografía TEM de una muestra preparada mediante FIB. Se muestra la sección adelgazada por completo.

limpio. Así se ha puesto de manifiesto en la micrografía de la figura 7, obtenida en una lámina individual. La microscopía de alta resolución (HREM) que se ha realizado en esta zona (figura 8) muestra que tanto el recubrimiento como el substrato son cristalinos en la interfase, y están perfectamente unidos.

La observación mediante TEM de la muestra preparada empleando FIB da lugar a similares resultados. En la figura 9, que presenta el área adelgazada en su totalidad, volvemos a ver la estructura laminar antes descrita. En la interfase, se observan áreas donde quedan gases atrapados, formando burbujas (figura 10), y otras limpias, como se pone de manifiesto en la micrografía de HREM de la figura 11. Es muy posible que la combinación de áreas de buen contacto con otras imperfectas den lugar en unas mejores propiedades mecánicas, aunque esta cuestión debe ser objeto de análisis específico. 


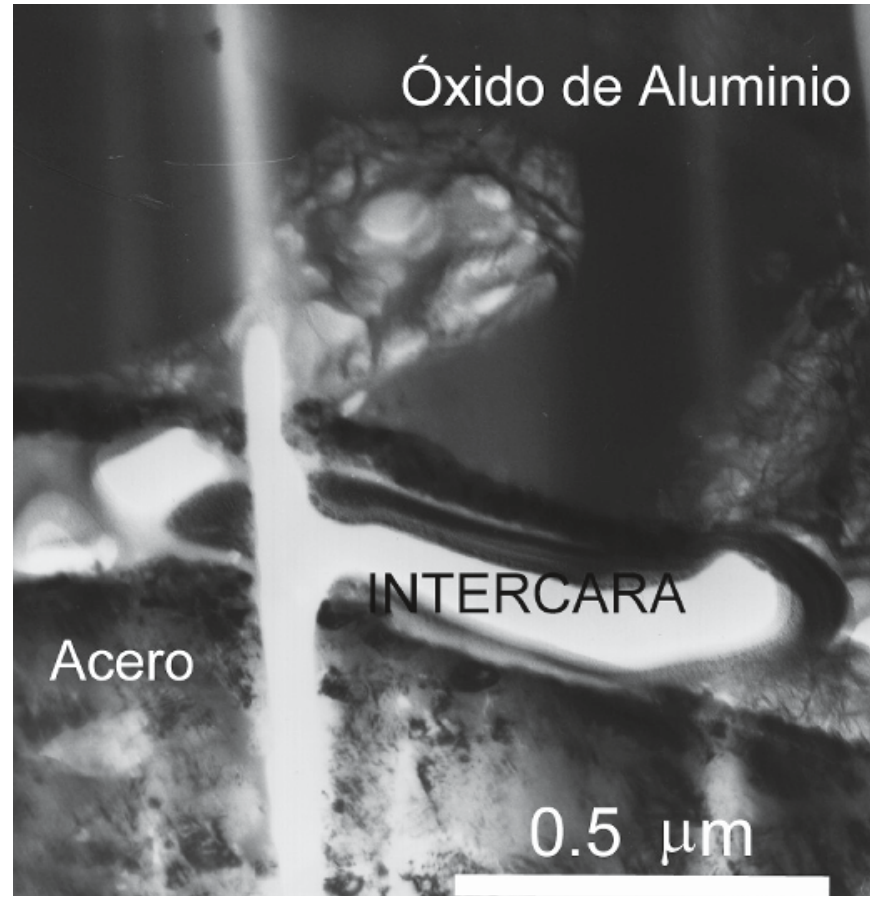

Figura 10.- Detalle de la misma micrografía (figura 9), mostrando gases atrapados en la interfase metal/cerámica.

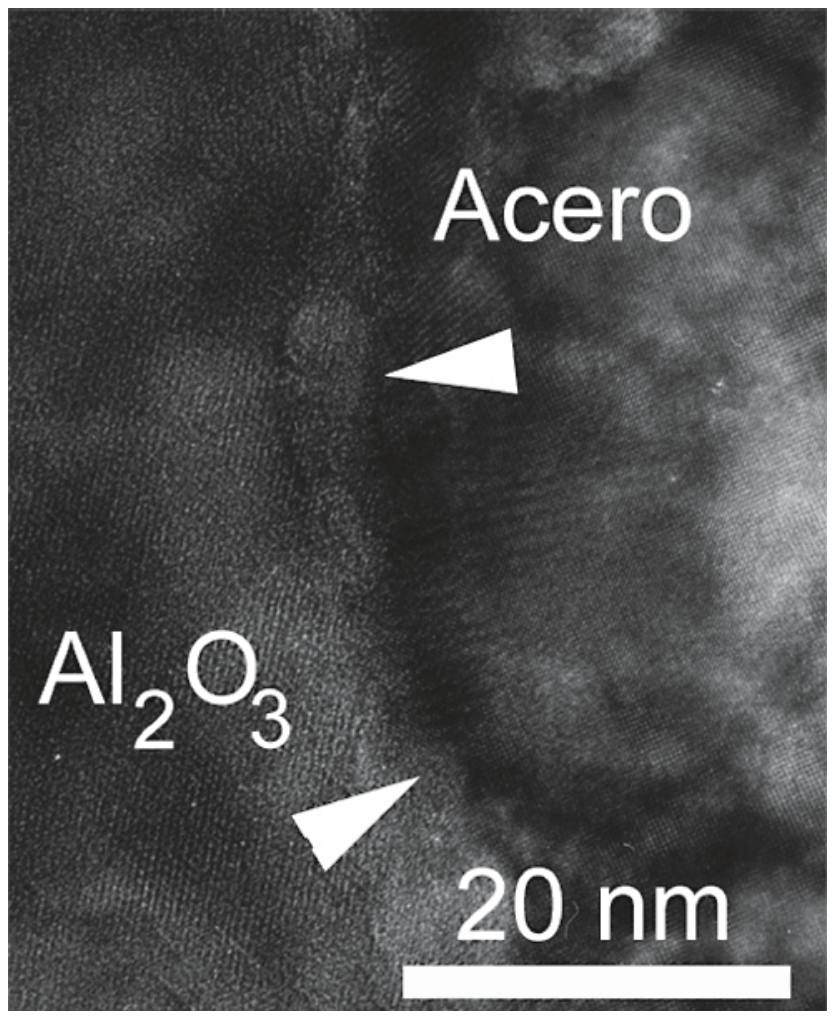

Figura 11.- Micrografía HREM de una muestra preparada mediante FIB, en la interfase metal/ cerámica. Las flechas blancas marcan la interfase.

\section{4.- DISCUSIÓN}

Tanto las técnicas de preparación de muestras mediante FIB como las técnicas convencionales, han permitido obtener láminas de buena calidad para ser observadas mediante TEM, lo que hace posible acceder a interesantes detalles microestructurales de recubrimientos preparados mediante SPPS.

Las técnicas convencionales dan lugar a áreas transparentes amplias, lo que ocurre especialmente en las muestras duplex. Esto permite, por ejemplo, estudiar con detalle las fases cristalinas del óxido de aluminio presentes en el recubrimiento. La preparación de estas láminas era más larga, y es difícil seleccionar zonas precisas de la interfase a las que se quiere acceder. Además, las interfases adelgazadas de peor contacto pueden despegarse, por lo que la impresión global podría resultar errónea.

Por otro lado, la técnica FIB permite un método más rápido de acceder zonas específicas de la interfase. Es posible además optimizar el tiempo de trabajo mediante la adecuada reducción del espesor del recubrimiento, por el pulido mecánico, por ejemplo. Así, se puede acceder a zonas donde el contacto entre los componentes es peor, y que no habrían resistido el tratamiento convencional. Se obtiene así una mejor apreciación sobre las propiedades reales de la interfase. Indicar también que el método SEM del FIB es de extraordinaria utilidad, ya que a costa de poco esfuerzo permite un seguimiento exhaustivo del adelgazamiento, y acceder a detalles que se revelan por el ataque preferencial de los iones en puntos concretos, con son las fronteras entre los splats.

La técnica de preparación de muestras para TEM mediante FIB presenta otras ventajas, como la posibilidad de su empleo en materiales porosos, o fuertemente agrietados, tradicionalmente de muy difícil manipulación.

\section{5.- CONCLUSIONES}

Los haces iónicos focalizados se emplean también con otros propósitos, además de los descritos, sobre todo en el campo de la microelectrónica (11) y la micromecanización (12), ya que permite realizar implatación iónica selectiva, microlitografía, etc. En este estudio hemos puesto de manifiesto además que son una alternativa interesante para la preparación muestras TEM de interfases metal/cerámica. Las técnicas aquí expuestas se han empleado además con éxito en el estudio de otros recubrimientos: óxido de circonio sobre aluminio, microlaminados de óxido de circonio/óxido de aluminio sobre acero, etc. No cabe duda de que la posibilidad de una buena caracterización microestructural es clave para una mejor compresión, aprovechamiento y diseño de las propiedades mecánicas y térmicas, probablemente las más importantes, en estos sistemas.

\section{AGRADECIMIENTOS}

Este trabajo se ha desarrollado con el patrocinio del U.S. Department. of Energy, Federal Technology Center, contrato DE-FC21-92MC29061, subcontracto 96-01-SR047. A.R.A.L. contó durante su estancia en NWU con una ayuda del Acuerdo de Intercambio y Cooperación entre la Universidad de Sevilla y Northwestern University. Los autores desean además expresar su agradecimiento a S.Wilhem, T.Bernecki, J.Mawdsley, Y.J.Su y R.Trice. 


\section{BIBLIOGRAFÍA}

1. P.J. Goodhew, Thin foil preparation for electron microscopy, Elsevier (1985) 206

2. R. Anderson y otros, Specimen preparation for TEM of materials, Vol. I, II, III, Materials Research Society 1988, 1990, 1992

3. T. Ishitani, T. Yagushi, “Cross sectional sample preparation by focused ion-beam: a review of ion-sample interaction", Micro. Res. and Tech., 35, 320-333 (1996)

4. T.F. Bernecki, D.R. Marron, "Small particle plasma spray apparatus, method and coated article", U.S. Patent 5744 777, 1998 y U.S. Patent 5858470 (1999)

5. N. Birks, G.H. Meier, F.S. Petit, "Forming continous alumina scales to protect superalloys", J.Met., 46 [12] 42 (1994)

6. T.E. Strangman, "Ceramic thermal barrier coatings systems and incorporation of an oxidation barrier layer", U.S. Patent 4880 614, (1989)
7. R. McPherson, "A review of microstructures and properties of plasma sprayed coatings", Surf.Coat.Tech. 39/40, 173-81 (1989)

8. R.W. Trice, K.T. Faber, "The role of lamelae morphology on the microstrutural development and mechanical properties of SPPS alumina", J.Am.Ceram.Soc., en imprenta

9. A. Ramírez de Arellano López, K.T. Faber, "Microstructural characterization of small particle plasma spray coatings", J.Am.Ceram.Soc., 82 [8], 2204-8 (1999)

10. T. Ishitani, T. Yagushi, H.Koike, "Focused ion-beam system for TEM sample preparation", Hitachi Review, 45 [1], 19-24 (1996)

11. L.H.Harriot, "Microfosused ion-beam applications in microelectronics", Appl. Surf.Sci., 36 432-42 (1989)

12. S.T. Davis, B. Khamsehpur, "Focused ion-beam machining and deposition for nanofabrication", Vacuum, 47 [5], 455-62 (1996)

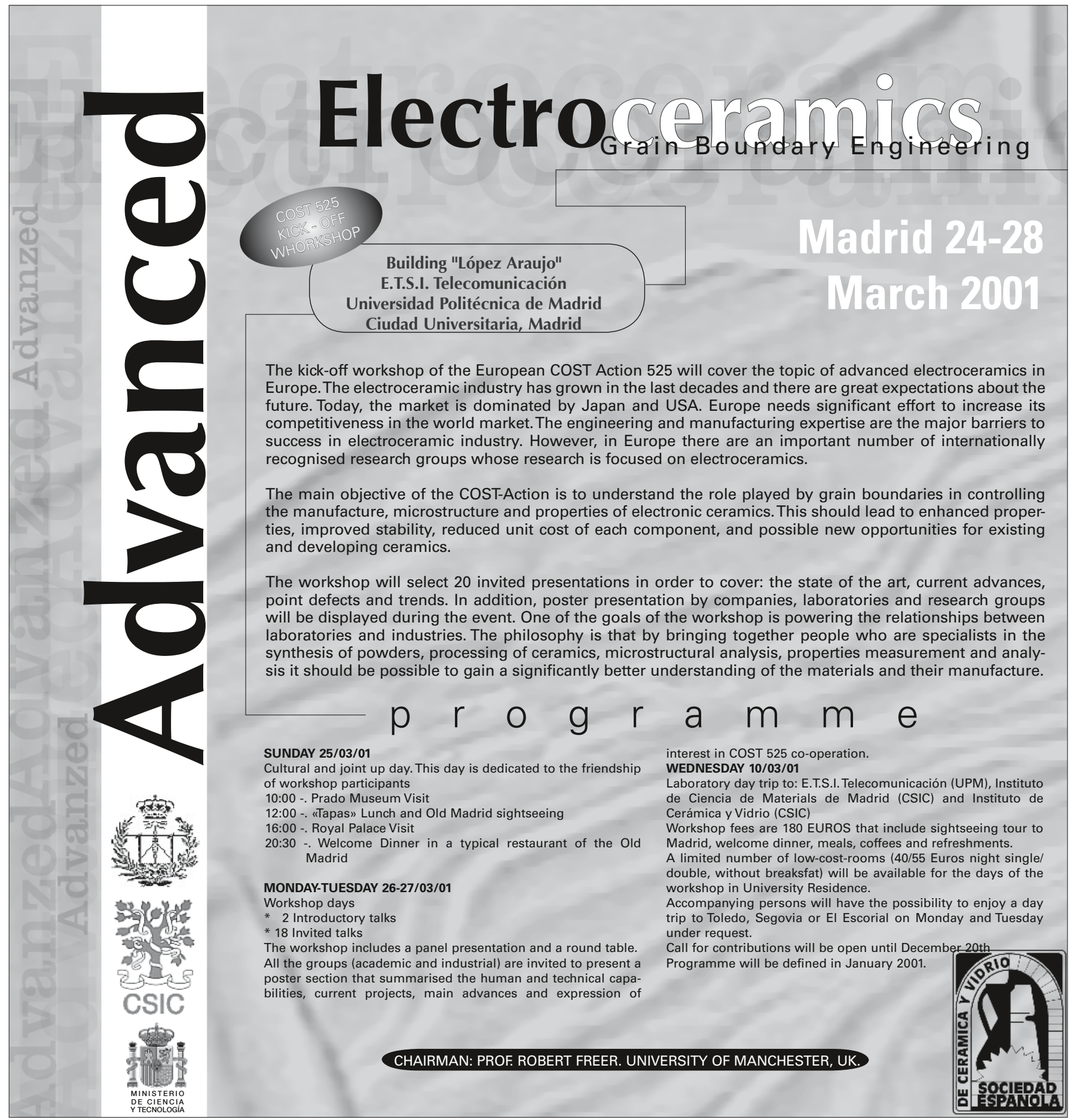

